Supporting Information

\title{
Baseline toxicity and volatility cut-off in reporter gene assays used for high-throughput screening
}

Beate I. Escher, ${ }^{\dagger \star *}$ Lisa Glauch, ${ }^{\dagger}$ Maria König, ${ }^{\dagger}$ Philipp Mayer ${ }^{\S}$ and Rita Schlichting ${ }^{\dagger}$ tDepartment of Cell Toxicology, Helmholtz Centre for Environmental Research - UFZ, Permoserstr. 15, DE-04318 Leipzig, Germany,

挨nvironmental Toxicology, Center for Applied Geoscience, Eberhard Karls University Tübingen, Hölderlinstr. 12, DE-72074 Tübingen, Germany

§Department of Environmental Engineering, Technical University of Denmark, Anker Engelunds Vej 1, DK-2800 Kongens Lyngby, Denmark

\section{Table of Content}

Section S1: Additional information on chemicals included in this study S2

Section S2: Detailed description of the dosing procedures and the bioassay workflow.

Section S3: Quantification of cytotoxicity by the IncuCyte S3 live-cell imaging system.

Section S4: Comparison of cell viability testing using the PrestoBlue $®$ assay and livecell imaging

Section S5: Dosing with the digital dispenser in comparison to dosing with automated pipetting

Section S6: Loss processes to the air and cross-contamination of adjacent wells S9 Section S7: Concentration-response curves for cytotoxicity of the baseline toxicants

Section S8: Applicability domain of the baseline toxicity QSARs with respect to the volatility cutoff 


\section{Section S1: Additional information on chemicals included in this study}

Table S1. Additional information on test chemicals.

\begin{tabular}{|c|c|c|c|c|}
\hline Chemical & CAS Number & SMILES & Source & Purity \\
\hline 2-Phenylphenol & $90-43-7$ & Oc1ccccc1c1ccccc1 & Sigma Aldrich & $99,6 \%$ \\
\hline 3-Nitroaniline & $99-09-2$ & $\mathrm{Nc} 1 \operatorname{cccc}(\mathrm{c} 1) \mathrm{N}(=\mathrm{O})=\mathrm{O}$ & Sigma-Aldrich & $98,0 \%$ \\
\hline 4-Chloro-3-methylphenol & $59-50-7$ & $\mathrm{Oc} 1 \mathrm{ccc}(\mathrm{c}(\mathrm{c} 1) \mathrm{C}) \mathrm{Cl}$ & Sigma-Aldrich & $\geq 98,0 \%$ \\
\hline 4-Pentylphenol & $14938-35-3$ & $\operatorname{cccccc} 1 \operatorname{ccc}(\operatorname{cc} 1) O$ & Sigma-Aldrich & $\geq 98,0 \%$ \\
\hline 2-Allylphenol & $1745-81-9$ & $\mathrm{C}=\mathrm{CCc} 1 \mathrm{ccccc} 10$ & Sigma-Aldrich & $98,0 \%$ \\
\hline 2-Butoxyethanol & $111-76-2$ & ccccocco & Sigma-Aldrich & $\geq 99,5 \%$ \\
\hline 2,4,5-Trichloroaniline & $636-30-6$ & $\operatorname{Clc} 1 c c(\mathrm{Cl}) \mathrm{c}(\mathrm{cc} 1 \mathrm{~N}) \mathrm{Cl}$ & Sigma-Aldrich & $99,1 \%$ \\
\hline Aniline & $62-53-3$ & Nc1ccccc1 & Sigma-Aldrich & $\geq 99,5 \%$ \\
\hline Quinoline & $91-22-5$ & $\mathrm{c} 1 \mathrm{ccc} 2 \mathrm{c}(\mathrm{c} 1) \mathrm{nccc} 2$ & Sigma-Aldrich & $\geq 98,0 \%$ \\
\hline Butan-1-ol & $71-36-3$ & Cccco & Sigma-Aldrich & $\geq 99,7 \%$ \\
\hline Pentan-3-ol & $584-02-1$ & $\operatorname{ccc}(\mathrm{CC}) \mathrm{O}$ & Sigma-Aldrich & $98,0 \%$ \\
\hline Nitrobenzene & $98-95-3$ & $\mathrm{O}=\mathrm{N}(=\mathrm{O}) \mathrm{c} 1 \operatorname{ccccc} 1$ & Sigma-Aldrich & $\geq 99,0 \%$ \\
\hline Hexan-1-ol & $111-27-3$ & cсcсcсо & Sigma-Aldrich & $\geq 99,9 \%$ \\
\hline 2-Nitrotoluene & $88-72-2$ & $\mathrm{O}=\mathrm{N}(=\mathrm{O}) \mathrm{c} 1 \mathrm{ccccc} 1 \mathrm{C}$ & Sigma-Aldrich & $\geq 99,0 \%$ \\
\hline V,N-Dimethylaniline & $121-69-7$ & $\mathrm{CN}(\mathrm{c} 1 \mathrm{ccccc} 1) \mathrm{C}$ & Sigma-Aldrich & $99,0 \%$ \\
\hline
\end{tabular}




\section{Section S2: Detailed description of the dosing procedures and the bioassay workflow.}

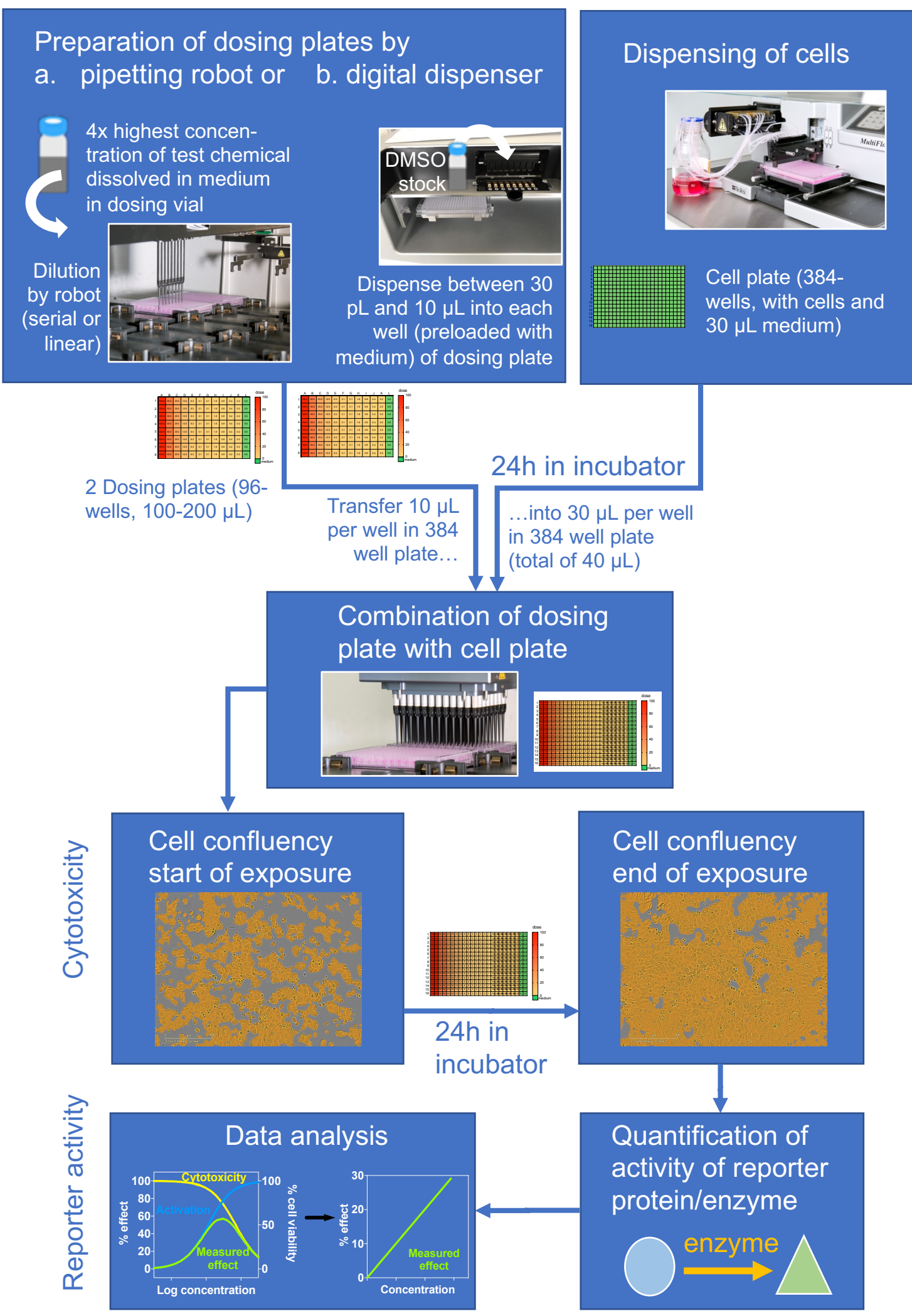

Figure S1. Workflow of a reporter gene assay with dosing using the Tecan D300e Digital Dispenser and the Hamilton Microlab Star pipetting platform. 


\section{Section S3: Quantification of cytotoxicity by the IncuCyte S3 live-cell imaging system.}

The IncuCyte S3 live-cell imaging system applied phase-contrast imaging to estimate the cell confluency in each well of a plate directly before dosing the chemicals and after $24 \mathrm{~h}$ of exposure to chemicals. A method for image analysis for each cell line was defined using a training set of images for each cell line consisting of at least 5 different images with differences in confluency and viability of the cells (Figure S2A). The raw image was analyzed after adjusting segmentation to set the general threshold between background and cells. Then the image analysis was fine-tuned by filling holes to fill gaps caused by low contrast and adjusting size of objects detected and area to assure that no debris or no empty areas between cells were marked as cell bodies. The area of the image covered with cells is marked in yellow after the application of the analysis method (Figure S2B). Each cell line-specific analysis method was applied to all 384well plates of the respective cell line measured in this study. An example of a well that was treated with a chemical and an example of unexposed cells is shown in Figure $\mathrm{S} 2 \mathrm{C}$ to demonstrate the capability of the imaging method to quantify cytotoxicity.
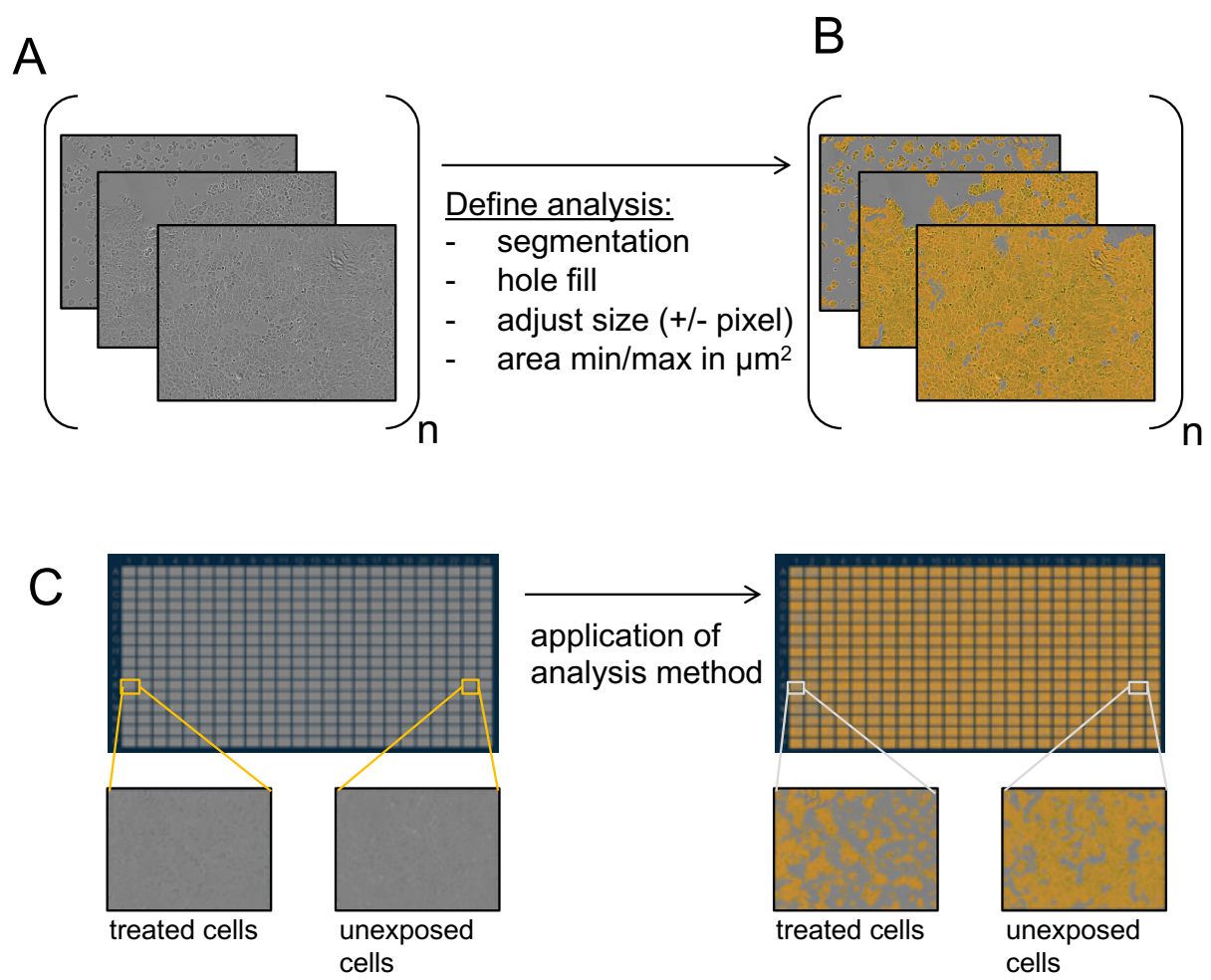

Figure S2. Method to estimate cell confluency by phase-contrast imaging. 


\section{Section S4: Comparison of cell viability testing using the PrestoBlue ${ }^{\circledR}$ assay and live-cell imaging}

An increase in cell viability of the controls and cells dosed with low concentrations of the test chemicals was detected after using PrestoBlue ${ }^{\circledR}$ Cell Viability Reagent (Thermo Fisher, Schwerte, Germany) for the detection of cytotoxicity. A crossexamination with the IncuCyte ${ }$ S3 Live-Cell Analysis System (Essen Bioscience, Ann Arbor, Michigan, USA) revealed that the increase in cell viability detected by PrestoBlue ${ }^{\circledR}$ was an artefact and it was impossible to derive $I_{10}$ values while the controls varied by more than $20 \%$ in case of the Presto Blue cytotoxicity measures (Figure S3). Therefore all experiments reported in this manuscript were performed using confluency of the cell layer expressed as percentage of confluency compared to unexposed controls (\% inhibition of cell viability) determined by acquisition of phase contrast images).

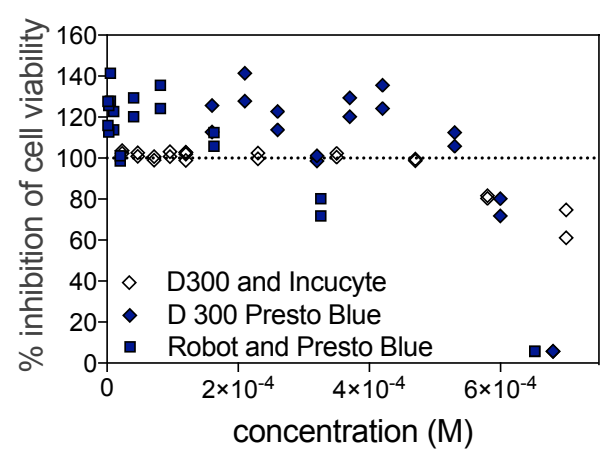

Figure S3. Inhibition of cell viability of AREc32 dosed with 2-phenylphenol determined with PrestoBlueß) (blue symbols) and live-cell imaging (empty diamonds). 


\section{Section S5: Dosing with the digital dispenser in comparison to dosing with automated pipetting}

In our previous work, we avoided DMSO as carrier of chemicals and environmental samples in in vitro bioassays because DMSO is already cytotoxic at much lower concentrations than methanol and because DMSO activated the oxidative stress response at concentrations below cytotoxic concentrations, ${ }^{1}$ reduced the metabolic activity of cells, ${ }^{2}$ stimulated anti-inflammatory activity, ${ }^{3}$ and interfered with the assessment of immunomodulatory effects. ${ }^{4}$ Our standard dosing process is to solvent exchange from methanol into bioassay medium prior to dosing 384-well plates that contain cells in a small volume of medium. This dosing procedure works well for extracts from complex environmental samples but has limitations for single chemical that are prone to precipitation. Therefore, we applied here different dosing methods comparing two different solvents, methanol and DMSO, as well as dosing by pipetting and by a digital dispenser based on inkjet technology.

We did not find any difference of cytotoxicity nor activation of oxidative stress response by DMSO and methanol as solvent for chemical stocks as exemplified for bisphenol A in AREc32 (Figure S4). When comparing the conventional dosing using the robotic system for preparing the dilution series from dosing vials with preequilibrated medium stocks at $4 x$ the highest concentration with the dosing method using the digital dispenser (Figure S1), we also did not observe any differences in the resulting concentration-response curves (Figure S4). We have performed such comparisons with all chemicals and most cell lines. Since there were no differences observed, all concentration-response curves in the following use all measured valid data, independent on the dosing procedure. The majority of experiments was for convenience performed with the digital dispenser.
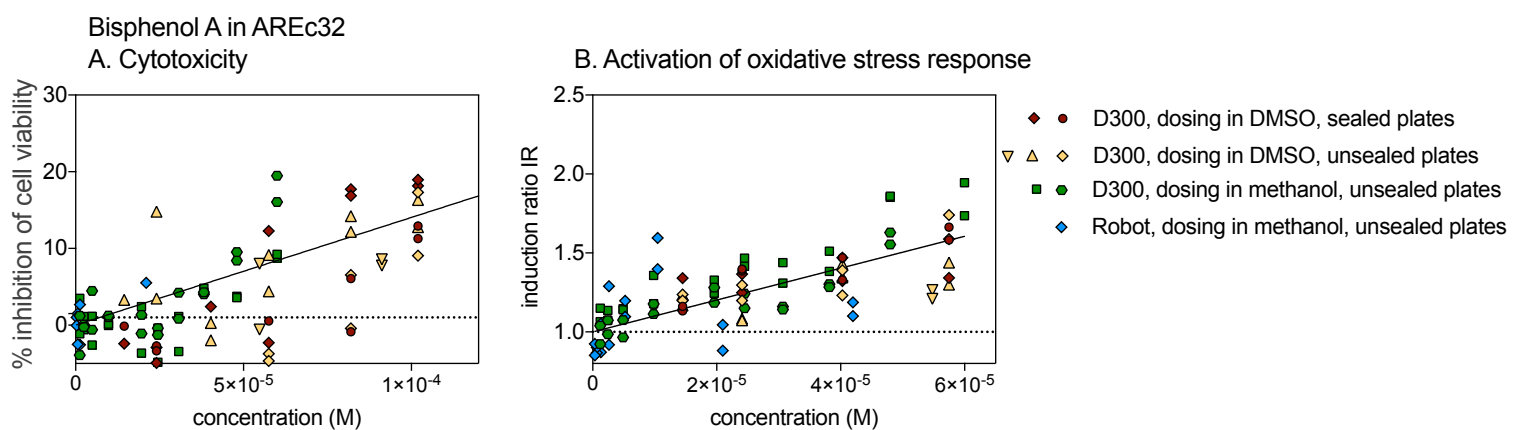

Figure S4. Comparison of dosing with the printer in comparison with conventional dosing using a serial dilution. 
The digital dispenser works in the volume range from $30 \mathrm{~nL}$ to $10 \mu \mathrm{L}$, hence it can easily be assured that the final DMSO concentration in the cell plate remains below $0.1 \%$ in all experiments. We chose not to complement the medium with a background DMSO dose but we evaluated the cytotoxicity of DMSO and assured that the highest applied amount of DMSO was not cytotoxic. The concentration-cytotoxicity curves for DMSO are depicted in Figure S5 and the $\mathrm{IC}_{10}$ for cytotoxicity ranged from 0.06 to 0.55 $\mathrm{M}$ for the eight cell lines evaluated, corresponding from $0.5 \%$ DMSO to $4 \%$ DMSO (Table S2), hence a maximal concentration of $0.1 \%$ DMSO appears to be a safe background dose.

Previous studies that have used the D300 dispenser for dosing reporter gene assays ${ }^{5}$ have directly dosed the DMSO stock into 384-well plates that contained cells that had been attached for a few hours. We opted instead to prepare dosing plates that were then transferred to the cell plates in one step using a 96-pipette head (Figure S1). This process appears more tedious at first sight but it avoids artifacts due to poor mixing that had been observed when DMSO was directly dosed. ${ }^{6}$ However, the additional step of transfer from dosing to cell plate method may exacerbate the evaporative and sportive losses of already difficult-to-test chemicals.

The maximal DMSO content in the cell plate was kept below $0.1 \%$ in all experiments, which is safely below the cytotoxicity $\mathrm{IC}_{10}$ (Table S2).

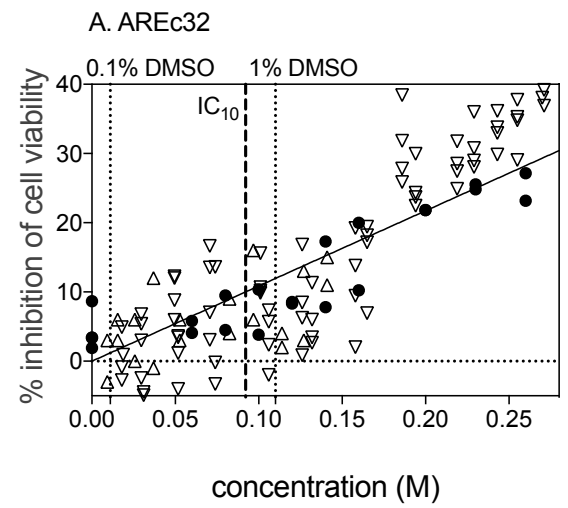

B. AhR-CALUX

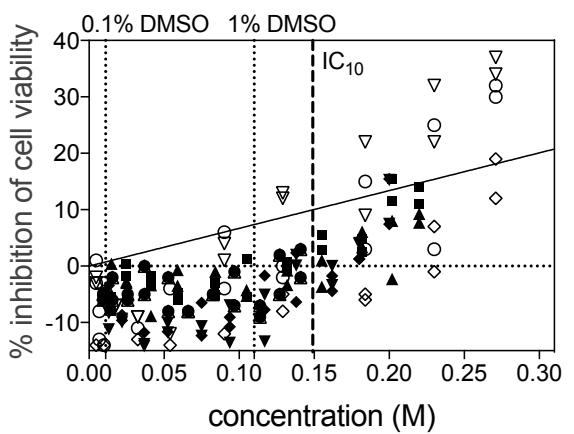

C. PPAR $\gamma-B L A$

D. AR-BLA
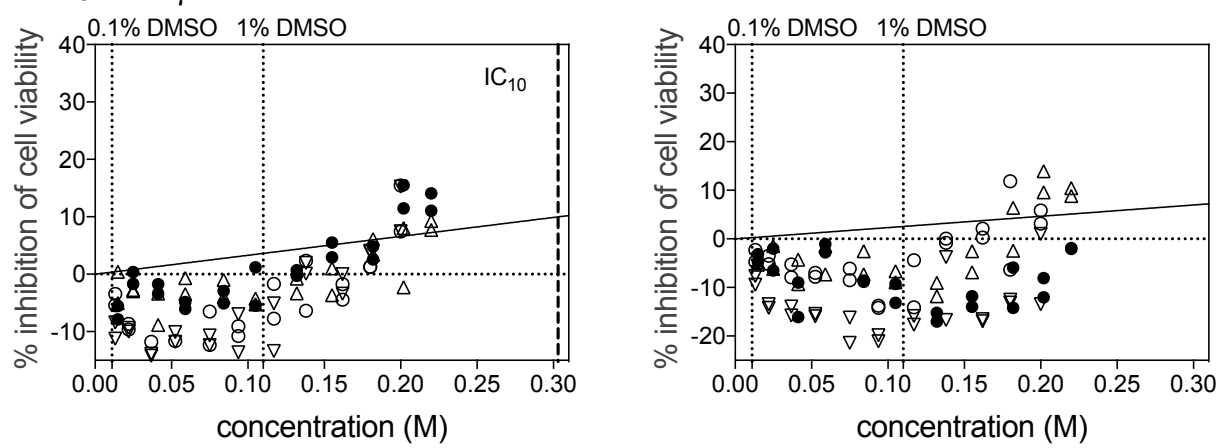
E. ER $\alpha-B L A$

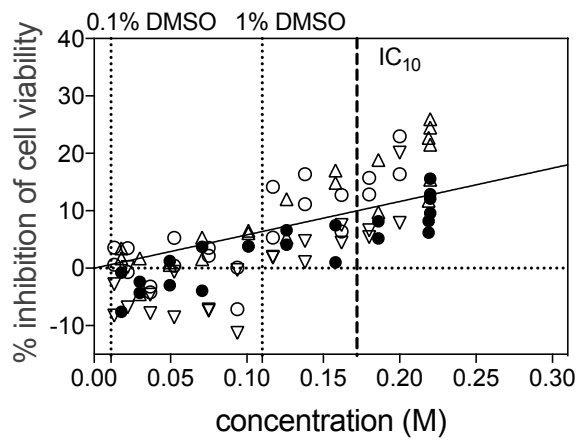

G. GR-BLA

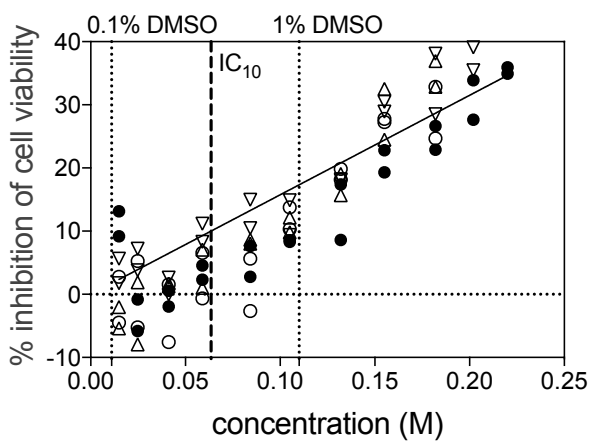

F. PR-BLA

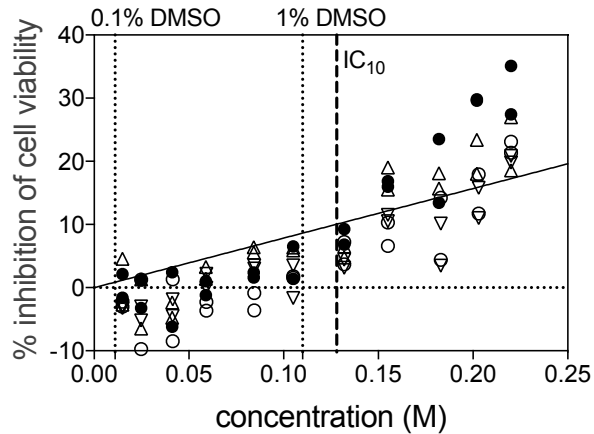

H. ARE-BLA

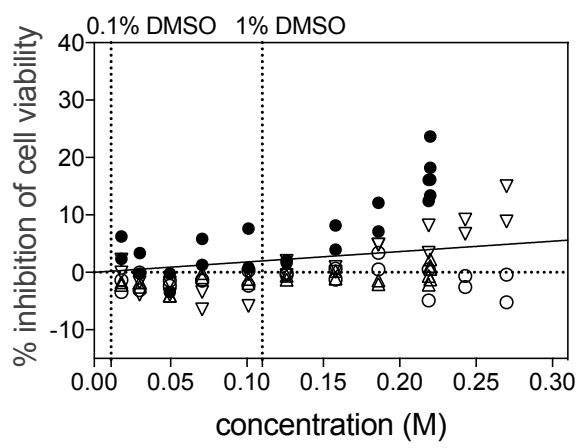

Figure S5. Concentration-effect curves of DMSO in all cell lines.

Table S2. Inhibitory concentrations for $10 \%$ reduction of cell viability $I C_{10}$ for DMSO in all cell lines.

\begin{tabular}{|c|c|c|c|c|c|c|c|c|}
\hline $\begin{array}{l}\text { Cyto- } \\
\text { toxicity of } \\
\text { DMSO }\end{array}$ & $\begin{array}{l}\text { AREc } \\
32\end{array}$ & $\begin{array}{l}\text { AhR- } \\
\text { CALUX }\end{array}$ & $\begin{array}{l}\text { PPAR } \gamma- \\
\text { BLA }\end{array}$ & AR-BLA & $\begin{array}{l}\text { ER } \alpha- \\
\text { BLA }\end{array}$ & $\begin{array}{l}\text { PR- } \\
\text { BLA }\end{array}$ & $\begin{array}{l}\text { GR- } \\
\text { BLA }\end{array}$ & $\begin{array}{l}\text { ARE- } \\
\text { BLA }\end{array}$ \\
\hline $\begin{array}{l}\mathrm{IC}_{10}(\mathrm{mM}) \\
\pm \mathrm{SEM}^{*}\end{array}$ & $92 \pm 4$ & $149 \pm 19$ & $303 \pm 50$ & $\begin{array}{c}430 \pm 15 \\
9\end{array}$ & $172 \pm 14$ & $128 \pm 8$ & $63 \pm 2$ & $\begin{array}{c}553 \pm 11 \\
2 \\
\end{array}$ \\
\hline \%CV & $4.9 \%$ & $12.7 \%$ & $16.5 \%$ & $37.1 \%$ & $8.3 \%$ & $6.4 \%$ & $3.5 \%$ & $20.3 \%$ \\
\hline $\begin{array}{l}I_{10} \\
\text { (\% DMSO) }\end{array}$ & $0.65 \%$ & $1.06 \%$ & $2.15 \%$ & $3.05 \%$ & $1.22 \%$ & $0.91 \%$ & $0.45 \%$ & $3.93 \%$ \\
\hline SEM $^{*}$ & $0.03 \%$ & $0.14 \%$ & $0.36 \%$ & $1.13 \%$ & $0.10 \%$ & $0.06 \%$ & $0.02 \%$ & $0.80 \%$ \\
\hline
\end{tabular}

*standard error of mean, derived by error propagation. 


\section{Section S6: Loss processes to the air and cross-contamination of adjacent wells}

Loss processes to air were systematically investigated by experiments, where only the six middle rows of a 384-well plate (row 7 to 12) were exposed to a dilution series of chemicals. Butoxyethanol, whose $K_{a w}$ was just around the previously defined "volatility cut-off" showed good concentration-cytotoxicity curves (Figure S6A) and no carry over to other wells, while Pentan-3-ol (Figure S6B) showed an appreciable loss, especially of the higher concentrations and N,N-Dimethylaniline (Figure S6C) even moved far across the plates with higher cytotoxicity measured at the end of the plate where lower dosages were applied.

Sealing of the plates with a breathable foil during the $24 \mathrm{~h}$ incubation positively affected Pentan-3-ol (Figure S6B) but had no effect on N,N-Dimethylaniline (Figure $\mathrm{S} 6 \mathrm{C})$.
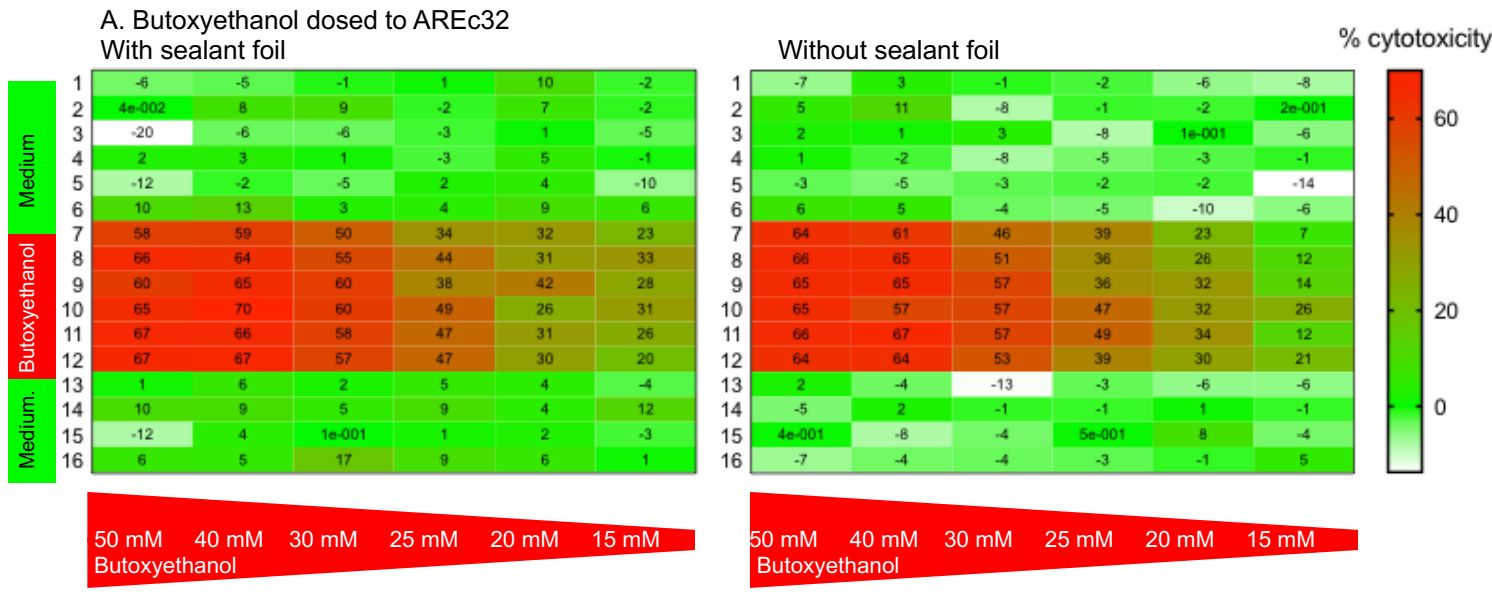

B. Pentan-3-ol dosed to AREc32 With sealant foil
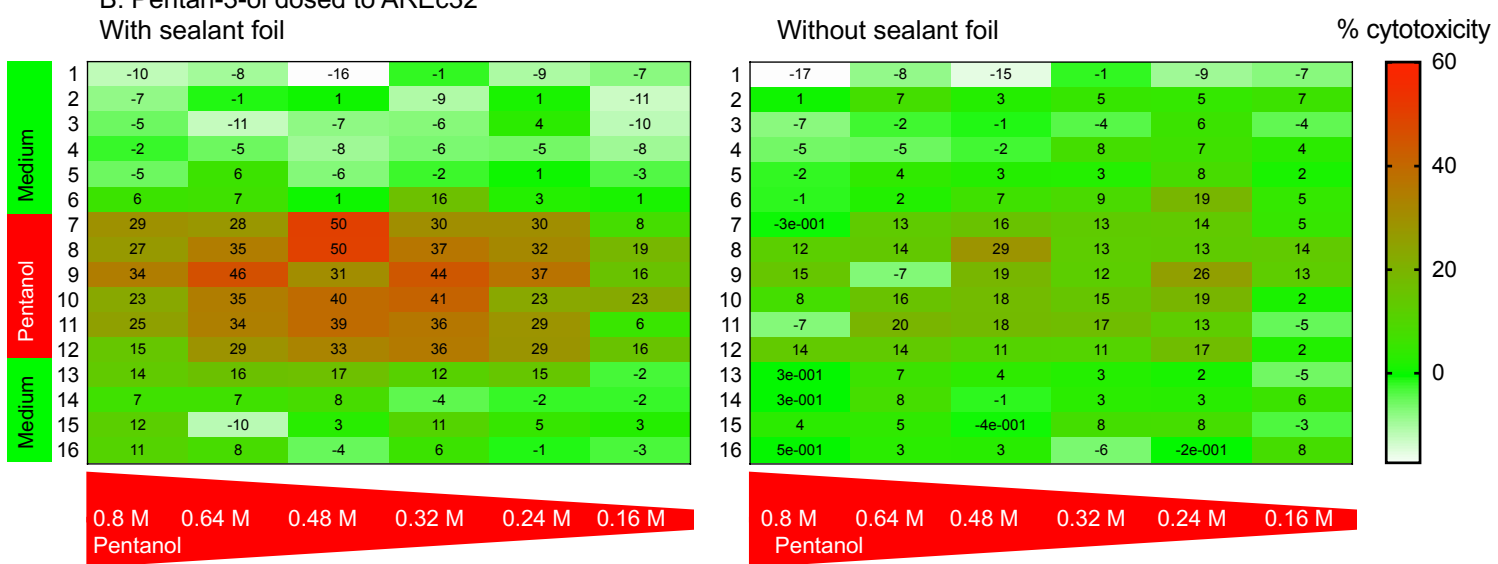
C. N,N-dimethylaniline dosed to AREc32 With sealant foil

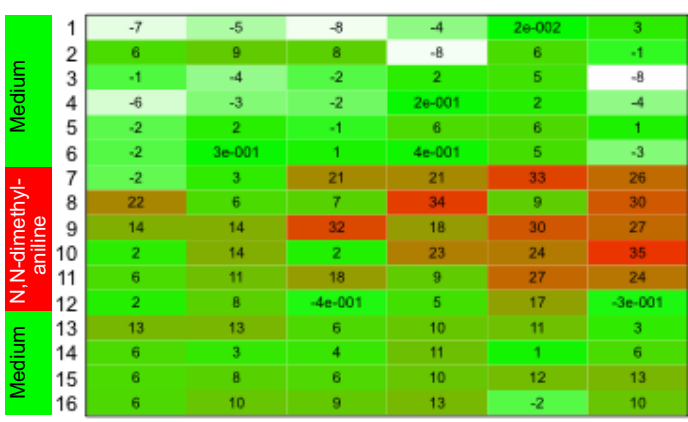

$\begin{array}{llllll}0.8 \mathrm{M} & 0.64 \mathrm{M} & 0.48 \mathrm{M} & 0.32 \mathrm{M} & 0.24 \mathrm{M} & 0.16 \mathrm{M}\end{array}$

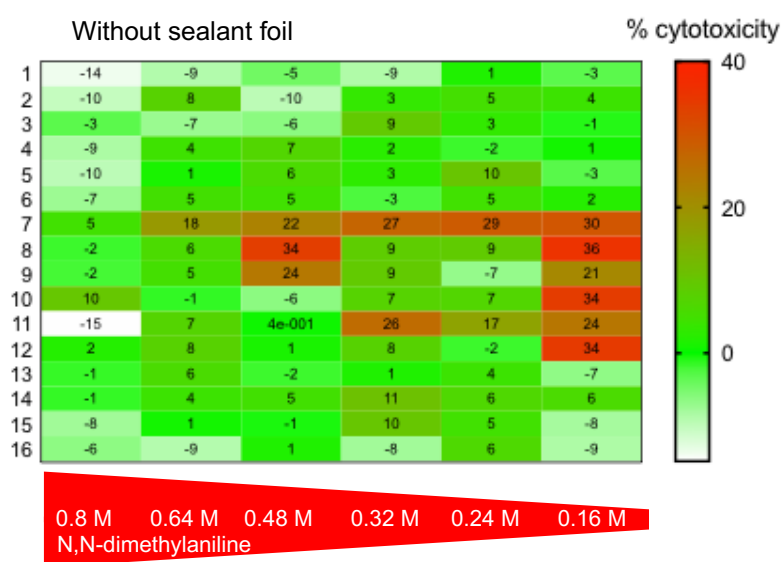

Figure S6. Empirical test for loss of chemicals (A. Butoxyethanol, B. Pentan-3-ol and C. N,N-Dimethylaniline) from wells and cross contamination of neighboring wells. Chemicals were dosed into rows 7-12 of a 384-well plate. The doses are given below the plate, the effects are \% cytotoxicity and every column is the average of two neighboring wells on the 384-well plate. 


\section{Section S7: Concentration-response curves for cytotoxicity of the baseline toxicants}
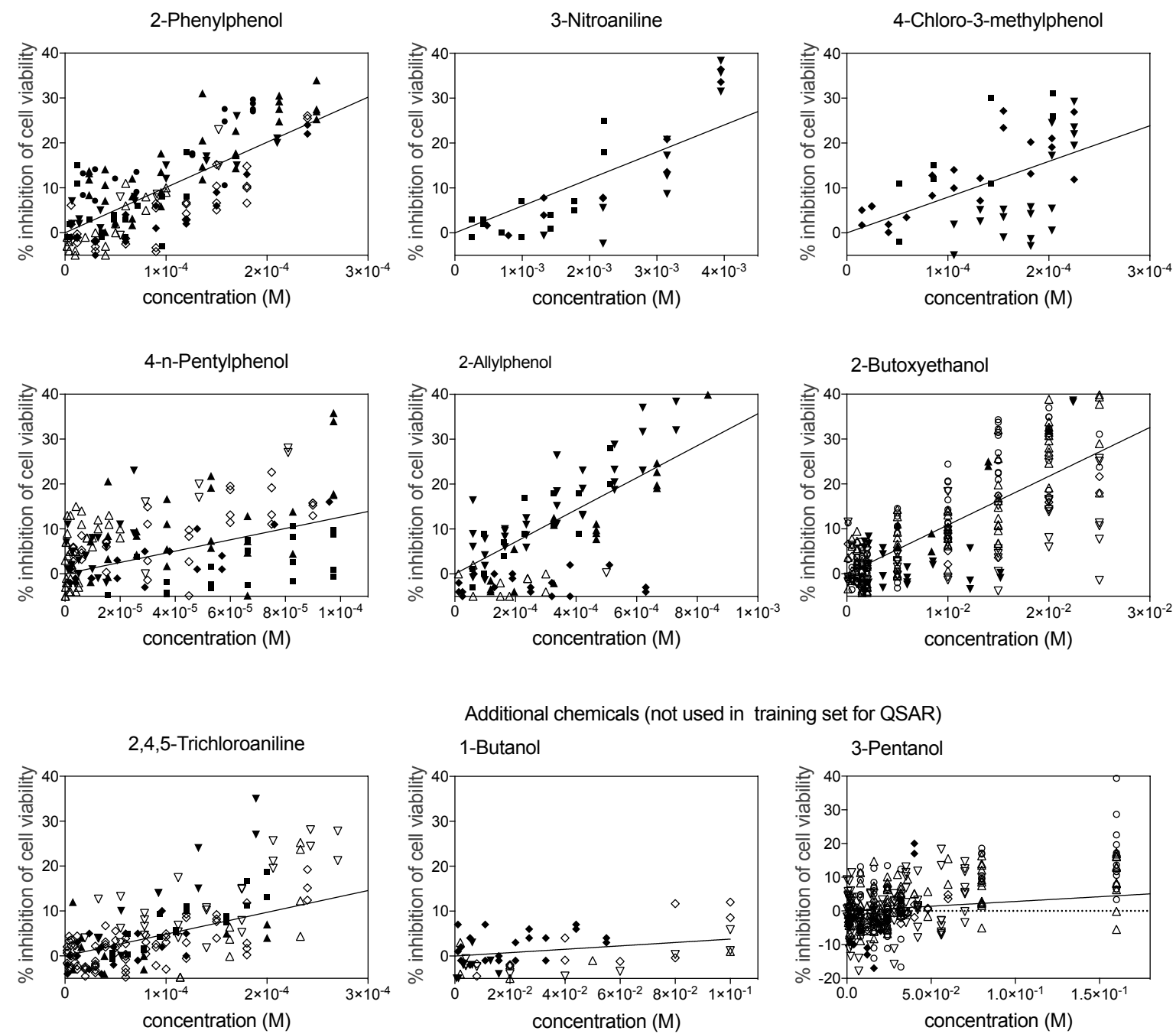

Figure S7. Concentration-cytotoxicity relationships for AREc32 of the chemicals used as QSAR training set and additional chemicals not included in QSAR but used for definition of the applicability domain. The different symbols represent independent experiments. 
2-Phenylphenol

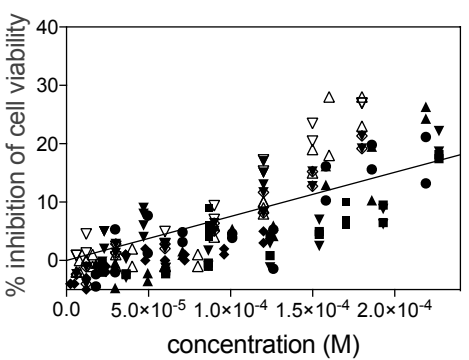

4-n-Pentylphenol

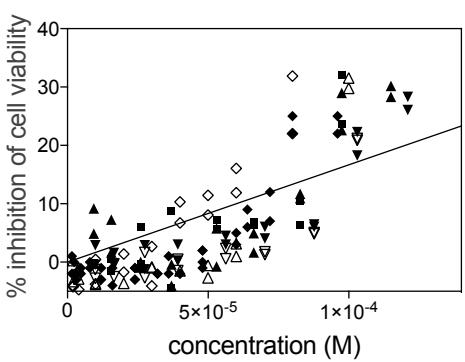

2,4,5-Trichloroaniline

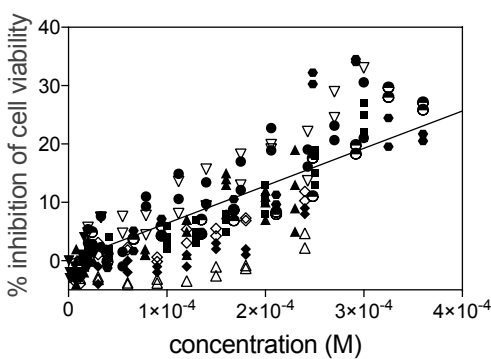

3-Nitroaniline

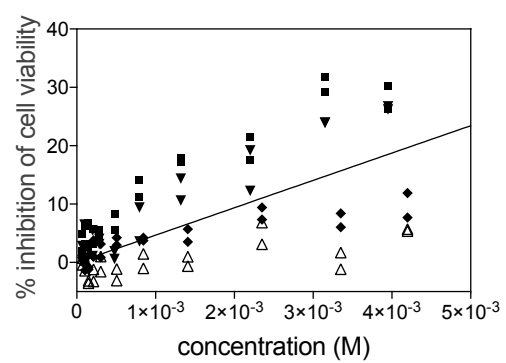

2-Allyiphenol

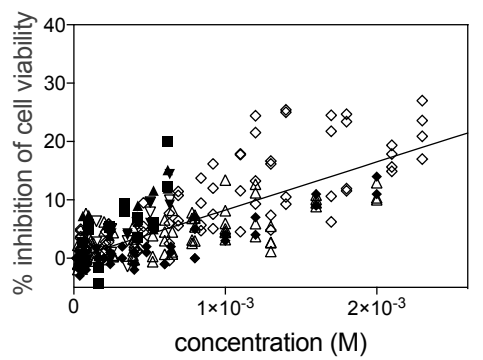

4-Chloro-3-methylphenol

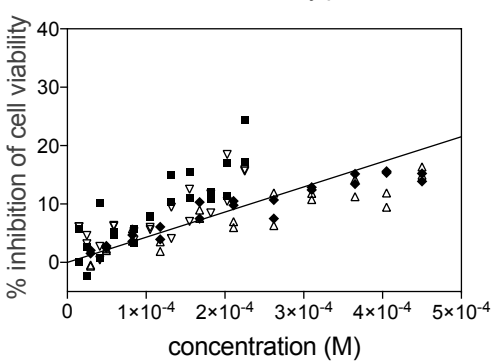

2-Butoxyethano

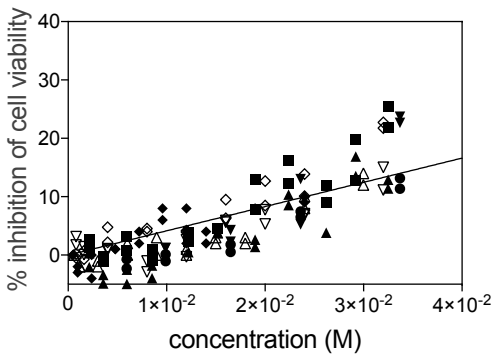

Additional chemicals (not used in training set for QSAR)

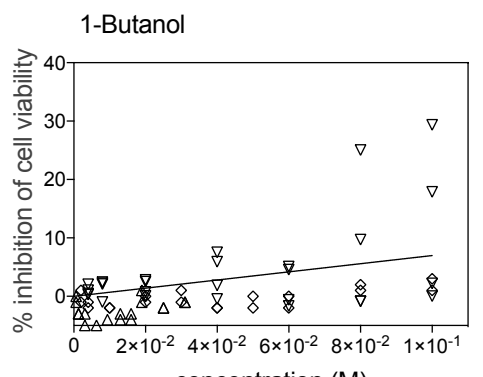

concentration (M)

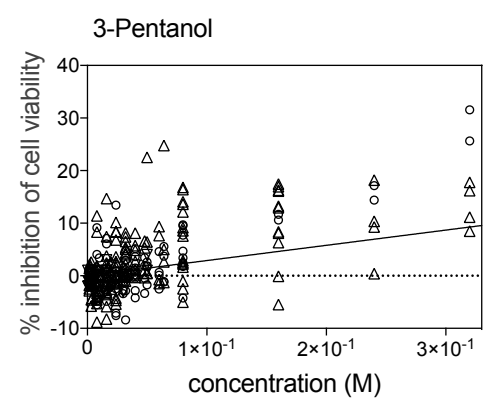

Figure S8. Concentration-cytotoxicity relationships for ARE-BLA of the chemicals used as QSAR training set and additional chemicals not included in QSAR but used for definition of the applicability domain. The different symbols represent independent experiments. 
2-Phenylphenol
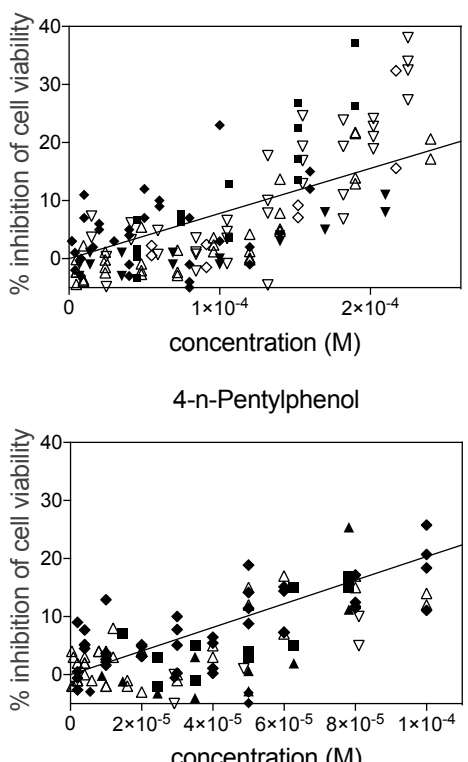

2,4,5-Trichloroaniline

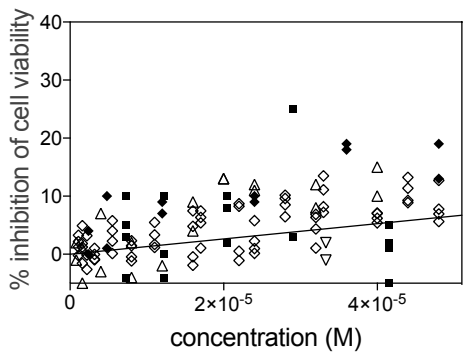

Additional chemicals (not used in training set for QSAR)
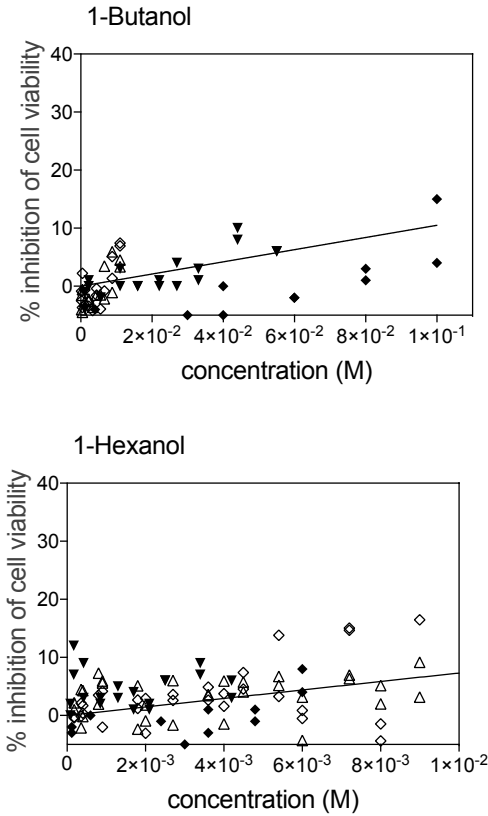

3-Nitroaniline

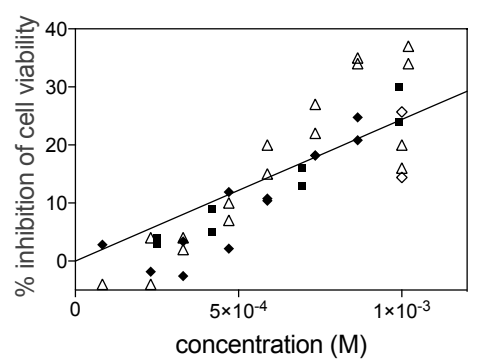

2-Allylphenol

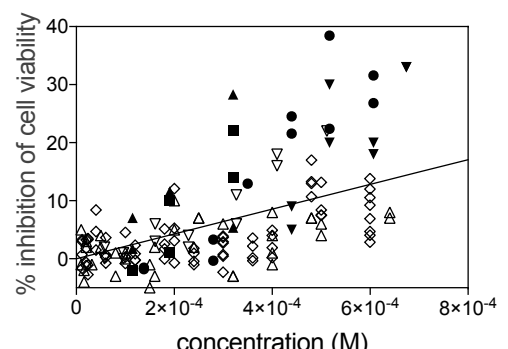

concentration (M)
4-Chloro-3-methylphenol

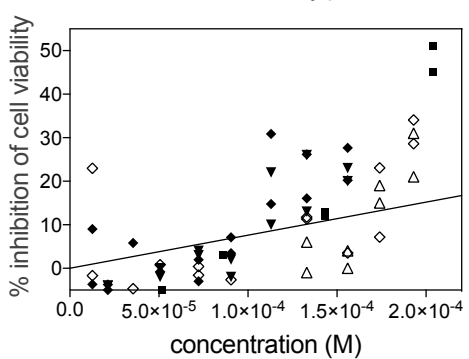

2-Butoxyethanol

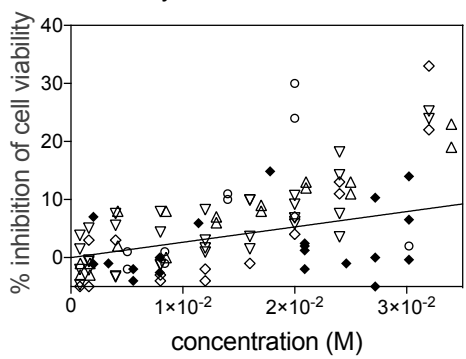

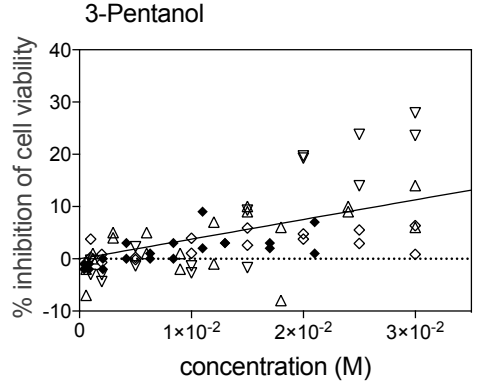

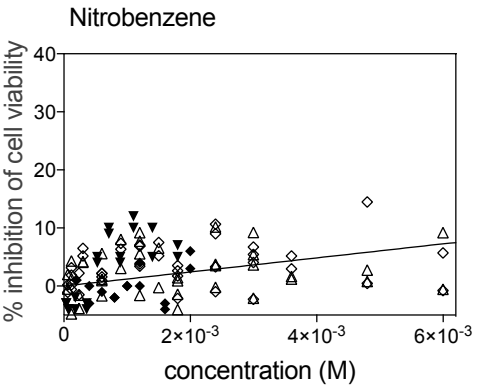

$\mathrm{N}, \mathrm{N}$-Dimethylaniline
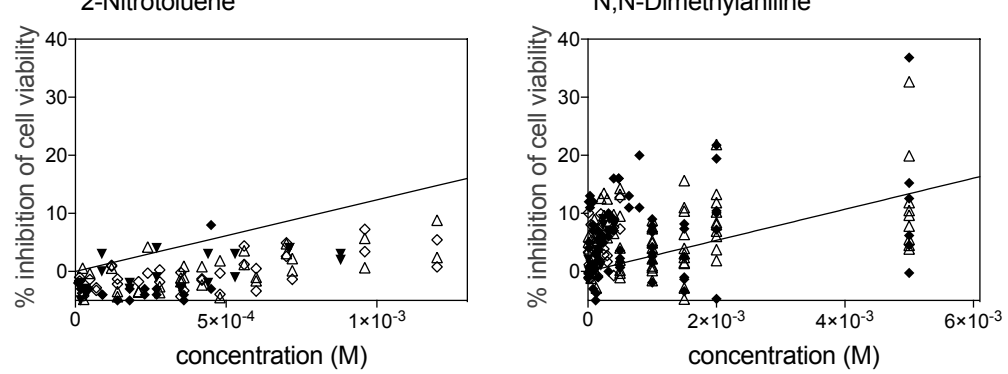

Figure S9. Concentration-cytotoxicity relationships for AhR-CALUX of the chemicals used as QSAR training set and additional chemicals not included in QSAR but used for definition of the applicability domain. The different symbols represent independent experiments. 

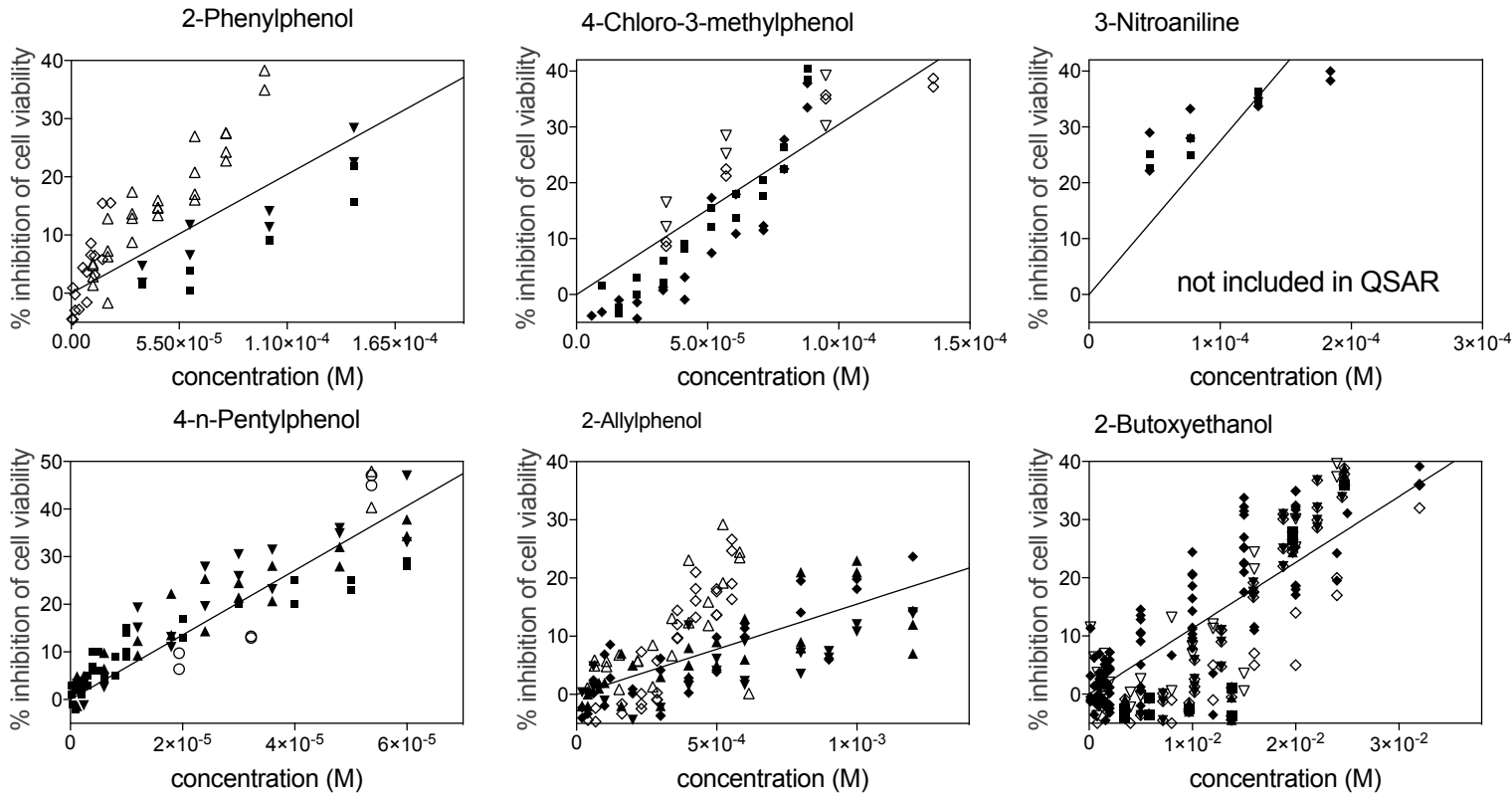

2-Butoxyethanol

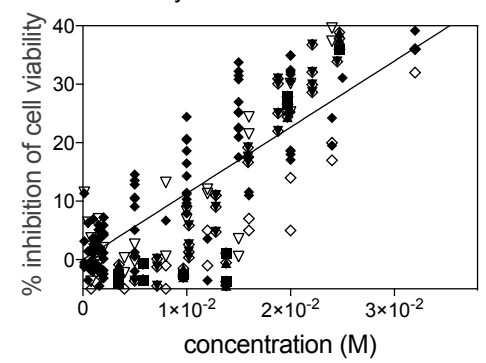

2,4,5-Trichloroaniline

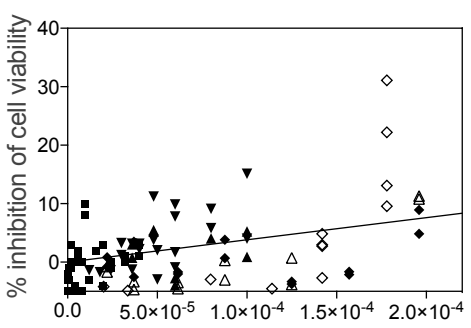

concentration (M)

Figure S10. Concentration-cytotoxicity relationships for PPAR $\gamma-B L A$ of the chemicals used as QSAR training set. The different symbols represent independent experiments.
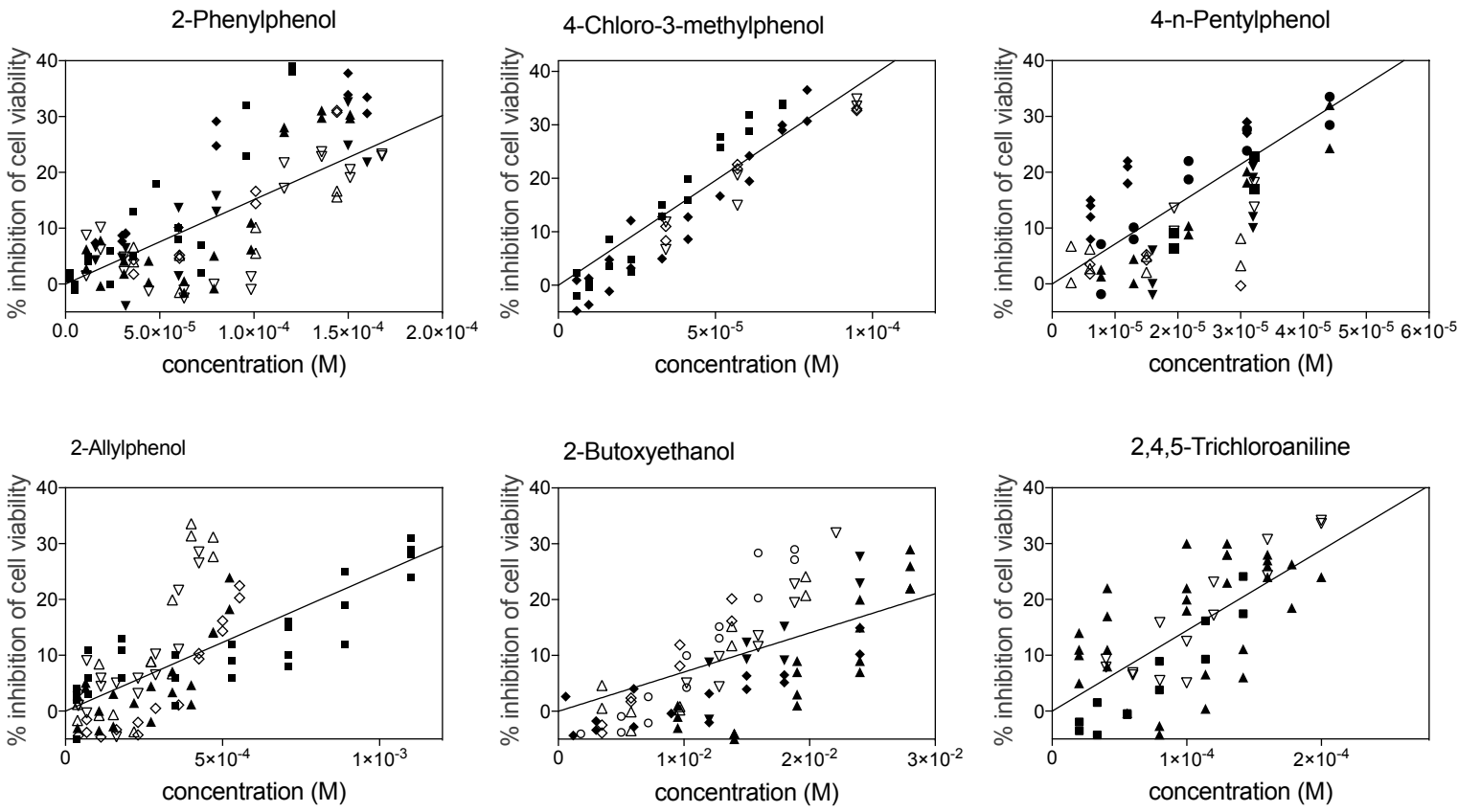

Figure S11. Concentration-cytotoxicity relationships for AR-BLA of the chemicals used as QSAR training set. The different symbols represent independent experiments. 

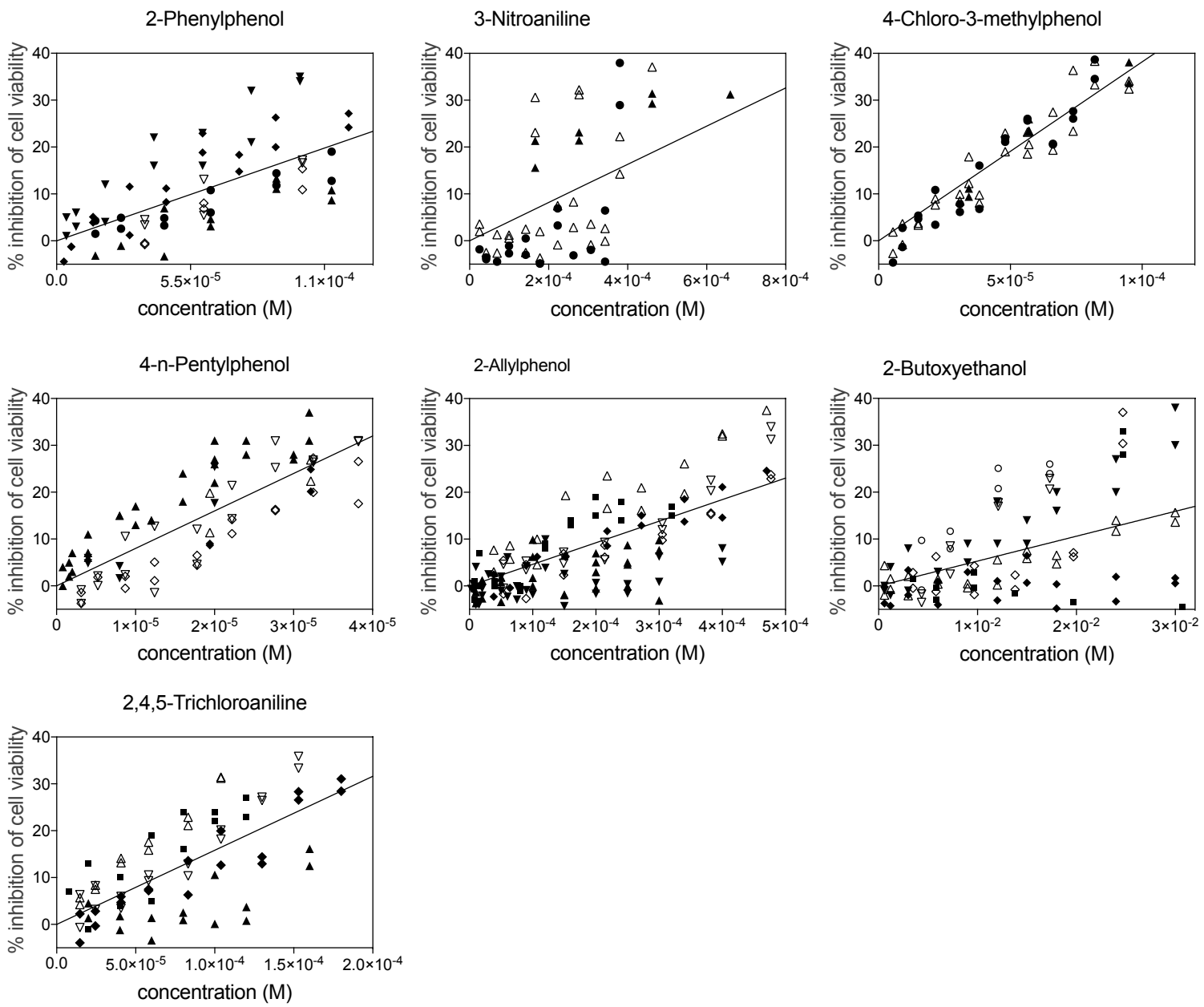

Figure S12. Concentration-cytotoxicity relationships for ER $\alpha-B L A$ of the chemicals used as QSAR training set. The different symbols represent independent experiments. 

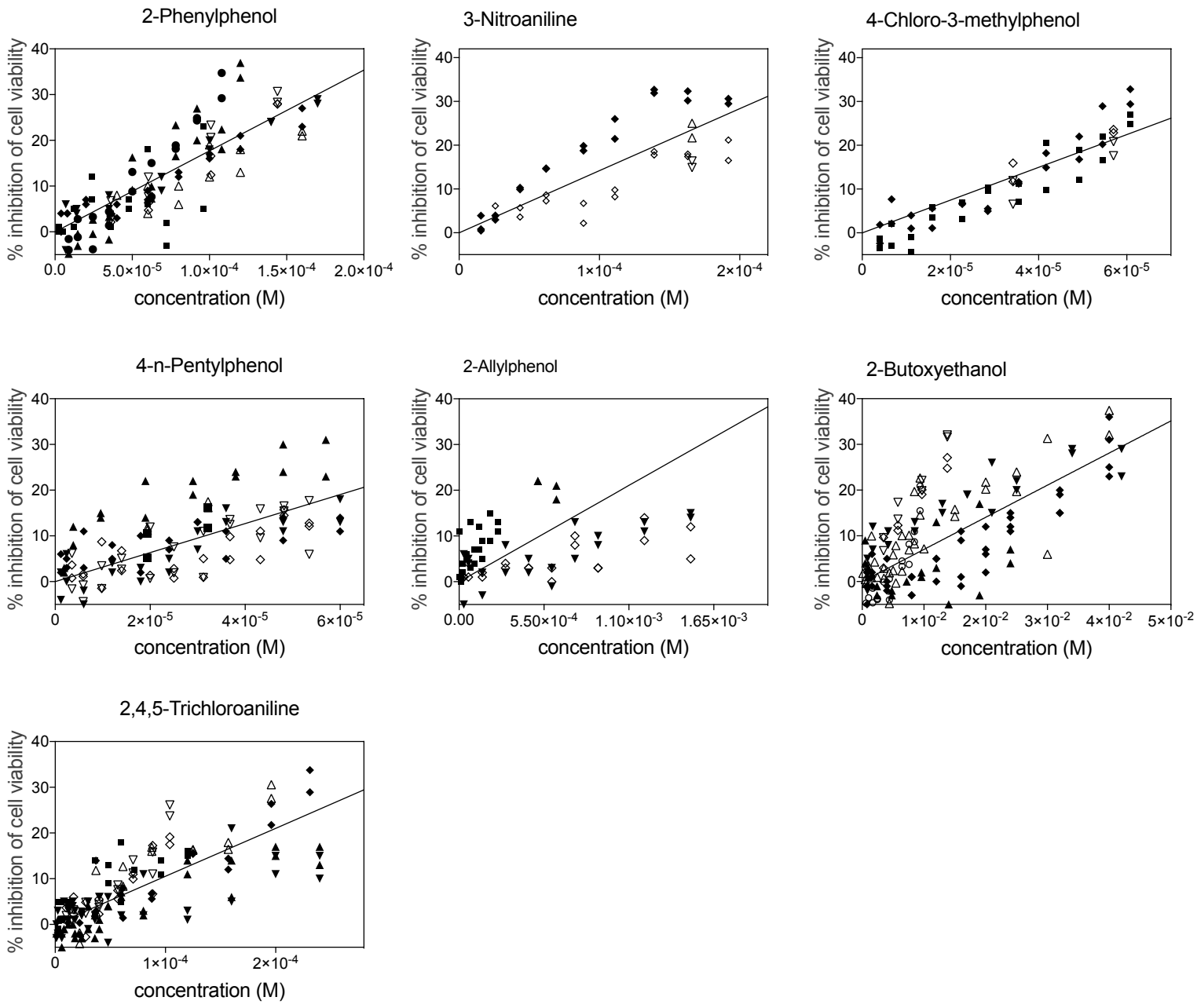

Figure S13. Concentration-cytotoxicity relationships for PR-BLA of the chemicals used as QSAR training set. The different symbols represent independent experiments. 

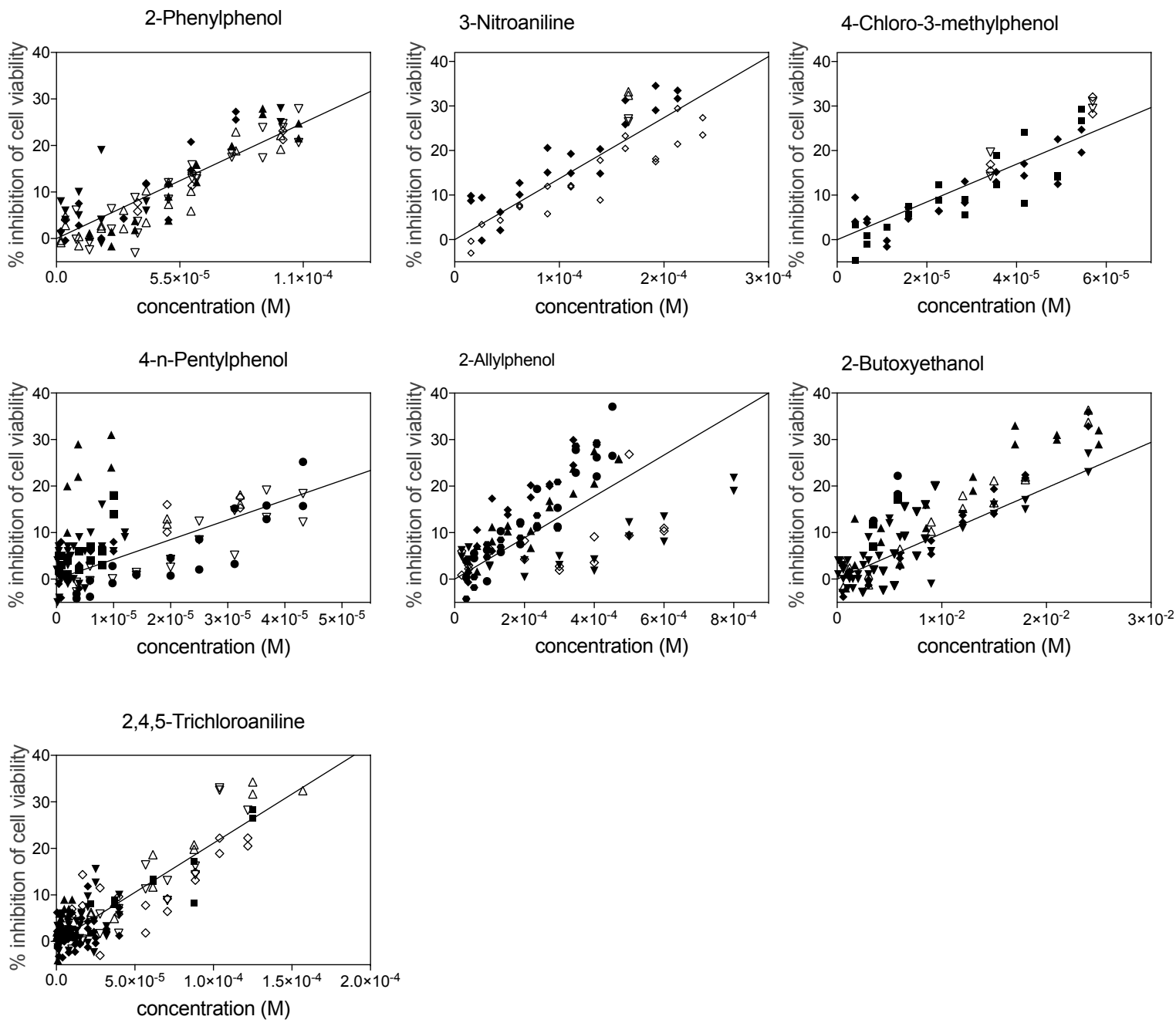

Figure S14. Concentration-cytotoxicity relationships for GR-BLA of the chemicals used as QSAR training set. The different symbols represent independent experiments. 


\section{Section S8: Applicability domain of the baseline toxicity QSARs with respect to the volatility cutoff}

The medium for AhR-CALUX and AREc32, which was supplemented with $10 \%$ FBS, retained more chemical in the plate and therefore all seven baseline toxicants and some of the six additional chemicals yielded $\mathrm{IC}_{10}$ values for cytotoxicity. For the GeneBLAzer assays the additional chemicals did not yield any concentration-response curves or, if they did, the derived $I_{10}$ values were higher than predicted by the baseline toxicity QSAR. Already for AhR-CALUX a slight trend towards $I C_{10}(Q S A R) / I C_{10}$ (experimental)-ratios smaller than one with smaller $K_{\text {medium/ar }}$ became apparent (Figure S15). This ratio is mathematically equivalent to the toxic ratio ${ }^{7}$ but since the deviation is due to an experimental artifact, namely the loss process to the air, we did not call it toxic ratio in this analysis but used it as a confirmation that the choice to limit the baseline toxicity QSAR to a training set of seven chemicals was an appropriate choice. In Figure S15, one can clearly perceive the trend of decreasing

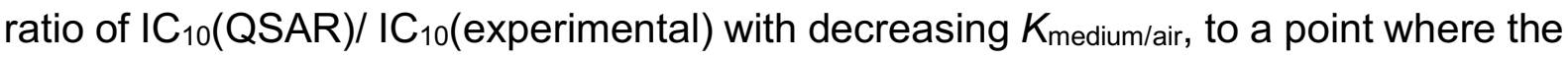
effect of many chemicals were not detectable any more (Table S3).
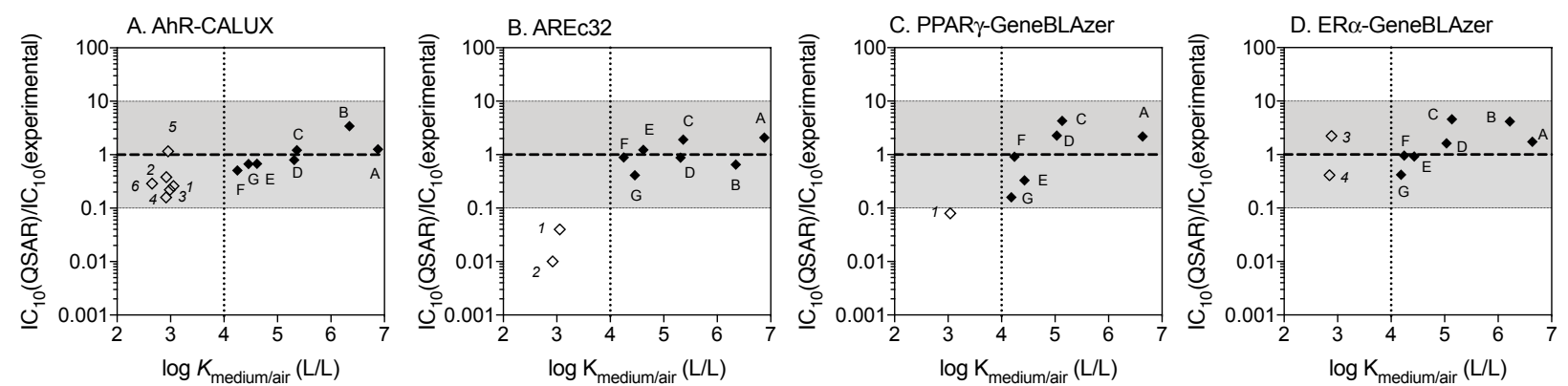

Figure 3. Ratio of $I C_{10}(Q S A R) / / C_{10}$ (experimental) as a measure of deviation from the baseline-toxicity QSAR for the baseline toxicants from the training set (black diamonds, (A) 2-Phenylphenol, (B) 3-Nitroaniline, (C), 4-Chloro-3methylphenol, (D) 4-Pentylphenol, (E) 2-Allylphenol, (F) 2-Butoxyethanol, (G) 2,4,5-Trichloroaniline) and additional, slightly more "volatile" baseline toxicants (empty diamonds (1) Butan-1-ol, (2) Pentan-3-ol, (3) Nitrobenzene, (4) Hexan-1-ol, (5) 2-Nitrotoluene, (6) N,N-Dimethylaniline). The vertical lines marks the $\mathrm{K}_{\text {medium/air }}$ cut-off of $10^{4}$. 
Table S3. Inhibitory concentrations $I C_{10}$ for cytotoxicity derived from the linear regressions of the concentration-cytotoxicity relationships depicted in Figures S8 to S15. - stands for tested but no evaluation possible.

$\mathrm{IC}_{10}(\mathrm{M})$
2-Phenylphenol
3-Nitroaniline
4-Chloro-3-methylphenol
4-Pentylphenol
2-Allylphenol
2-Butoxyethanol
2,4,5-Trichloroaniline
Butan-1-ol
Pentan-3-ol
Nitrobenzene
Hexan-1-ol
2-Nitrotoluene
N,N-Dimethylaniline

$\begin{array}{llll}\text { AREc32 } & \text { ARE-BLA } & \text { AhR-CALUX } & \text { PPAR } \gamma-B L A \\ 9.9 \pm 0.4 \cdot 10^{-5} & 1.3 \pm 0.1 \cdot 10^{-4} & 1.3 \pm 0.9 \cdot 10^{-4} & 5.4 \pm 0.3 \cdot 10^{-5} \\ 1.7 \pm 0.2 \cdot 10^{-3} & 2.1 \pm 0.2 \cdot 10^{-3} & 4.1 \pm 0.3 \cdot 10^{-4} & - \\ 1.3 \pm 0.1 \cdot 10^{-4} & 2.3 \pm 0.1 \cdot 10^{-4} & 1.6 \pm 0.4 \cdot 10^{-4} & 3.3 \pm 0.2 \cdot 10^{-5} \\ 7.9 \pm 0.8 \cdot 10^{-5} & 6.0 \pm 0.4 \cdot 10^{-5} & 4.9 \pm 0.3 \cdot 10^{-5} & 1.5 \pm 0.5 \cdot 10^{-4} \\ 2.8 \pm 0.4 \cdot 10^{-4} & 1.2 \pm 0.5 \cdot 10^{-4} & 4.7 \pm 0.6 \cdot 10^{-4} & 6.4 \pm 0.3 \cdot 10^{-4} \\ 9.2 \pm 0.4 \cdot 10^{-3} & 2.4 \pm 0.1 \cdot 10^{-2} & 3.8 \pm 0.9 \cdot 10^{-2} & 8.8 \pm 0.4 \cdot 10^{-3} \\ 2.1 \pm 0.2 \cdot 10^{-4} & 1.6 \pm 0.1 \cdot 10^{-4} & 7.8 \pm 0.7 \cdot 10^{-5} & 2.6 \pm 0.7 \cdot 10^{-4} \\ 2.7 \pm 1.3 \cdot 10^{-1} & 1.4 \pm 0.2 \cdot 10^{-1} & 9.5 \pm 2.7 \cdot 10^{-2} & - \\ 3.5 \pm 0.8 \cdot 10^{-2} & 2.1 \pm 0.6 \cdot 10^{-2} & 2.7 \pm 0.3 \cdot 10^{-2} & - \\ - & - & 8.3 \pm 1.3 \cdot 10^{-3} & - \\ - & - & 1.4 \pm 0.2 \cdot 10^{-3} & - \\ - & - & 8.1 \pm 6.2 \cdot 10^{-4} & - \\ - & - & 3.7 \pm 0.6 \cdot 10^{-3} & -\end{array}$

AR-BLA
$6.6 \pm 0.3 \cdot 10^{-5}$
-
$2.5 \pm 0.1 \cdot 10^{-5}$
$1.4 \pm 0.1 \cdot 10^{-4}$
$2.2 \pm 0.1 \cdot 10^{-4}$
$1.4 \pm 0.1 \cdot 10^{-2}$
$6.9 \pm 0.5 \cdot 10^{-5}$
-
-
-
-
-
-

$5.6 \pm 0.3 \cdot 10^{-5}$

$5.7 \pm 0.2 \cdot 10^{-5}$

$2.5 \pm 0.4 \cdot 10^{-4}$

$2.6 \pm 0.1 \cdot 10^{-5}$

$2.7 \pm 0.1 \cdot 10^{-5} \quad 2.4 \pm 0.1 \cdot 10^{-5}$

$3.1 \pm 0.2 \cdot 10^{-5} \quad 2.3 \pm 0.2 \cdot 10^{-4}$

$5.2 \pm 0.3 \cdot 10^{-4} \quad 2.3 \pm 0.1 \cdot 10^{-4}$

$1.4 \pm 0.1 \cdot 10^{-2} \quad 1.0 \pm 0.1 \cdot 10^{-2}$

$6.3 \pm 0.3 \cdot 10^{-5} \quad 9.5 \pm 0.5 \cdot 10^{-5} \quad 4.7 \pm 0.2 \cdot 10^{-5}$

$6.3 \pm 0.3 \cdot 10^{-5}$

$-$

$-$

$-$ 


\section{References}

1. Escher, B. I.; Dutt, M.; Maylin, E.; Tang, J. Y. M.; Toze, S.; Wolf, C. R.; Lang, M., Water quality assessment using the AREc32 reporter gene assay indicative of the oxidative stress response pathway. J. Environ. Monitor. 2012, 14, (11), 2877-85. 2. Ferk, P.; Daris, B., The influence of dimethyl sulfoxide (DMSO) on metabolic activity and morphology of melanoma cell line WM-266-4. Cellular and Molecular Biology 2018, 64, (11), 41-43.

3. Costa, L. D.; Ottoni, M. H. F.; dos Santos, M. G.; Meireles, A. B.; de Almeida, V. G.; Pereira, W. D.; de Avelar-Freitas, B. A.; Brito-Melo, G. E. A., Dimethyl Sulfoxide (DMSO) Decreases Cell Proliferation and TNF-alpha, IFN-gamma, and IL-2 Cytokines Production in Cultures of Peripheral Blood Lymphocytes. Molecules 2017, 22, (11).

4. Timm, M.; Saaby, L.; Moesby, L.; Hansen, E. W., Considerations regarding use of solvents in in vitro cell based assays. Cytotechnology 2013, 65, (5), 887-894. 5. Jones, R. E.; Zheng, W.; McKew, J. C.; Chen, C. Z., An Alternative Direct Compound Dispensing Method Using the HP D300 Digital Dispenser. Jala 2013, 18, (5), 367-374.

6. Tanneberger, K.; Rico-Rico, A.; Kramer, N. I.; Busser, F. J.; Hermens, J. L. M.; Schirmer, K., Effects of solvents and dosing procedure on chemical toxicity in cellbased in vitro assays. Environ. Sci. Technol. 2010, 44, 4775-4781.

7. Maeder, V.; Escher, B. I.; Scheringer, M.; Hungerbuhler, K., Toxic ratio as an indicator of the intrinsic toxicity in the assessment of persistent, bioaccumulative, and toxic chemicals. Environ. Sci. Technol. 2004, 38, (13), 3659-3666. 